\title{
L-carnitine treatment in a seriously ill cancer patient with severe hyperthyroidism
}

\author{
Rene Chee, ${ }^{1}$ Ravin Agah, ${ }^{2}$ Roberto Vita, ${ }^{3}$ Salvatore Benvenga ${ }^{3-5}$ \\ ${ }^{1}$ Department of Developmental Biology, Stanford University, School of Medicine; ${ }^{2}$ Internal Medicine, Palo Alto Medical \\ Foundation, Mountain View; CA, USA; ${ }^{3}$ Section of Endocrinology, Department of Clinical \& Experimental Medicine, \\ University of Messina; ${ }^{4}$ Master Program on Childhood, Adolescence \& Women's Endocrine Health, University of \\ Messina; ${ }^{5}$ Interdepartmental Program of Molecular \& Clinical Endocrinology and Women's Endocrine Health, A.O.U. \\ Policlinico G. Martino; Messina, Italy
}

\begin{abstract}
OBJECTIVE: To report a case of vaccine-induced Graves' disease successfully managed with L-carnitine and propranolol and without antithyroid drugs (ATDs). ATDs sometimes need to be used at low doses or can be contraindicated/refused. One of the ancillary compounds available is $\mathbf{L}$-carnitine. $\mathbf{L}$-carnitine is a naturally occurring quaternary amine, which acts by impairing thyroid hormone access to the cell nucleus. REPORT: A 32-year-old Chinese woman with a synovial sarcoma received radiotherapy, chemotherapy and experimental immunotherapy. Two months after the start of immunotherapy, she developed autoimmune hyperthyroidism [thyroid-stimulating immunoglobulins $($ TSI $)=152 \%$, normal values $<140$ ]. Left untreated, hyperthyroidism worsened (TSI $=248 \%$ ), so that for 3 months she took L-carnitine $(1-4 \mathrm{~g} / \mathrm{d})$ and propranolol $(20-80 \mathrm{mg} / \mathrm{d})$. Though the hyperthyroidism worsened biochemically (FT4 $>50 \mathrm{pg} /$ $\mathrm{ml}$, FT3 $>20 \mathrm{pg} / \mathrm{ml}$, TSI $=501 \%$ ), it was tolerated very well clinically. Fearing a life-threatening thyroid storm, she agreed to have, while still hyperthyroid, total thyroidectomy. The operation was uneventful. CONCLUSIONS: This case expands previous observations involving two more patients who survived thyroid storms while being treated with L-carnitine (combined with low doses of ATD). Taking also into account that tissue concentrations of L-carnitine decrease in hyperthyroidism, there is room for wide therapeutic use of L-carnitine in several hyperthyroidism settings.
\end{abstract}

Key words: Autoimmunity, Graves' disease, L-carnitine, Thyrotoxicosis

\section{INTRODUCTION}

Medical treatment of hyperthyroidism is today

\section{Address for correspondence:}

Roberto Vita, Endocrinologia, Dipartimento di Medicina Clinica e Sperimentale, A.O.U. G. Martino, Viale Gazzi, 98125, Messina, Italy; Tel.: +3909.0221.3560,

Fax: +3909.0221.3518, E-mail: roberto.vita@yahoo.it

Received 13-03-2013, Accepted 05-07-2013 mainly managed via antithyroid drugs (ATDs) and beta-blockers, both of which, however, have side effects. ${ }^{1}$ In addition, ATDs are contraindicated when hyperthyroidism is due to leakage of preformed thyroid hormones, such as in thyroiditis. ATDs are also contraindicated in the exaggerated response of the "healthy moiety" of nuclear thyroid hormone receptors to the high concentrations of thyroid hormones, a 
response associated with thyroid hormone resistance syndrome. The most recent survey available shows stronger support than in the past by thyroidologists for ATDs over ${ }^{131}$ I-radiotherapy and thyroidectomy as the primary therapy for Graves' disease-related hyperthyroidism. ${ }^{2}$ In the most severe form of hyperthyroidism, which has a mortality rate as high as $75 \%$, corticosteroids are also used because of the advantage they offer in inhibiting T4-to-T3 conversion. ${ }^{3}$

The only advances that have been made in recent years in the medical therapy of hyperthyroidism concern the ancillary, adjunctive side of management and include benzodiazepines, ${ }^{4,5}$ cholestyramine ${ }^{6,7}$ or colestipol, ${ }^{8}$ glucomannan, ${ }^{9}$ and L-carnitine. ${ }^{10-13}$ Benzodiazepines have been proposed because the onset and exacerbations or relapses of Graves' disease-related hyperthyroidism are frequently triggered by stressful events and because benzodiazepines interfere with thyroid hormone binding to the thyroid hormone receptors. ${ }^{4,5,13}$ Cholestyramine and colestipol, two anion exchange resins that sequester bile acids and iodothyronines, decrease the serum levels of both $\mathrm{T} 4$ and $\mathrm{T} 3$ by reducing the circulating quota that derives from the entero-hepatic circulation of the two hormones, this circulation being increased in hyperthyroidism. The gel-forming fiber glucomannan acts with a similar sequestering effect. Unlike these sequestrants, and similarly to benzodiazepines, Lcarnitine does not decrease the circulating levels of thyroid hormones. L-carnitine acts in the periphery, since it impairs thyroid hormone entry into the cells and, to a greater extent, thyroid hormone entry into the cell nucleus. ${ }^{10}$

The effectiveness of L-carnitine has been proven in iatrogenic hyperthyroidism ${ }^{11}$ and in a Graves' disease patient who experienced three subsequent thyroid storms while taking L-carnitine in association with low doses of methimazole and supportive therapy. ${ }^{12}$ For the relapsers, the common denominator was the comparison with the onset (first episode) of hyperthyroidism. Indeed, these patients noticed that they tolerated far better the hyperthyroid symptoms and did not experience the haematologic or hepatic or cutaneous side effects from ATDs they had experienced previously. However, none of them had taken L-carnitine without combination with an ATD, and none had been so seriously ill as the patient described here.
This patient is a proof of principle that a seriously ill patient, such as one with metastasized malignancy, can tolerate high levels of thyroid hormones for months if tissues are "protected" from excessive amounts of thyroid hormones.

\section{Report}

A synovial sarcoma of the right infratemporal fossa was diagnosed intraoperatively in a 32-year-old Chinese woman. Because of the high rate of recurrence and metastasis, she received intensity-modulated radiation therapy to the head and neck region (total dose 66 Gy) and chemotherapy (doxorubicin plus ifosfamide plus mesna as a chemoprotective agent, for 5 cycles). Leukopenia, with neutrophils often below $1,500 / \mathrm{mm}^{3}$ and thrombocytopenia, with platelets below $140,000 / \mathrm{mm}^{3}$, ensued. Because of the poor prognosis of synovial sarcoma and because the general conditions remained fair (Eastern Cooperative Oncology Group score grade 1 ), the patient pursued experimental immunotherapy with the NY-ESO-1 peptide vaccine. The vaccine is based on an immunogenic peptide derived from the cancer-testis antigen NY-ESO-1, which stimulates the host immune system to mount a humoral and cytotoxic $\mathrm{T}$ lymphocyte response to cells expressing NY-ESO-1 antigen, resulting in tumor cell lysis. ${ }^{14}$ The vaccine was administered 5 times 3 weeks apart. She underwent 5 additional weeks of immunotherapy.

Subsequently, thyroid dysfunction was clinically suspected because of previous radiotherapy to the head and neck. The biochemical assays performed were consistent with mild hyperthyroidism: TSH $0.13 \mathrm{mU} / \mathrm{L}$ (normal values $0.34-4.82$ ), FT3 $4.8 \mathrm{pg} / \mathrm{ml}$ (7.4 pmol/L) [normal values $2.3-4.3 \mathrm{pg} / \mathrm{ml}$ (3.5-6.6 $\mathrm{pmol} / \mathrm{L}$ )], thyroid-stimulating immunoglobulins (TSI) $152 \%$ (normal values $<140$ ). Three weeks later, TSH was $0.02 \mathrm{mU} / \mathrm{L}$, FT3 $5.9 \mathrm{pg} / \mathrm{ml}$, with FT4 $20.4 \mathrm{pg} / \mathrm{ml}$ (26.2 pmol/L) [normal values 5.9-16.1 pg/ml (7.6-20.7 $\mathrm{pmol} / \mathrm{L})$ ], while in February TSH and FT4 had been normal $(2.5 \mathrm{mU} / \mathrm{L}$ and $11.8 \mathrm{pg} / \mathrm{ml}$, respectively). At the end of October 2010, TSH was $<0.02 \mathrm{mU} / \mathrm{L}$, FT3 $11.7 \mathrm{pg} / \mathrm{ml}$, FT4 $32.6 \mathrm{pg} / \mathrm{ml}$, and TSI 248\%. Neck ultrasonography revealed an enlarged thyroid $(27 \mathrm{ml})$ with diffuse inhomogeneity, and no discrete nodules, further corroborating Graves' disease. Not wanting to compromise the effects of immunotherapy and fearful of ${ }^{131} \mathrm{I}$ and of the haematological side effects of 
ATDs, she refused both ATDs and ${ }^{131}$ I, but accepted the beta-blocker (propranolol, 20 to $80 \mathrm{mg} /$ day).

She was started on oral L-carnitine (Sigma-tau, Gaithersburg, Md) at the initial daily dose of $4 \mathrm{~g} / \mathrm{d}$ (2 $\mathrm{g}$, twice a day). It was at this point that she contacted S.B., with whom she continued to correspond by email. Clinical improvement was such that L-carnitine was reduced to $1 \mathrm{~g}$ /day (Figure 1). This improvement included reduction of palpitations, tachycardia, asthenia and thigh myopathy. Figure 2 illustrates changes of biochemical indices [TSH, FT3, FT4, alkaline phosphatase(ALP), alanine-aminotransferase (ALT), aspartate-aminotransferase (AST) and clinical parameters (pulse rate, body weight and thyroid volume)]. Red blood cells, white blood cells and platelets and haemoglobin / haematocrit were similar to those recorded previously: $4.70 \pm 0.23 v s .4 .74 \pm$ 0.23 million $/ \mathrm{mm}^{3}, 3.6 \pm 0.65 \mathrm{vs} .3 .2 \pm 0.65$ thousand/ $\mathrm{mm}^{3}, 157 \pm 13$ vs. $170 \pm 36$ thousand $/ \mathrm{mm}^{3}$, and 12.3 \pm 0.5 vs. $11.9 \pm 0.6 \mathrm{~g} / \mathrm{dL}, 36.5 \pm 1.6 v s .36 .5 \pm 1.5 \%$.

The hyperthyroidism worsened biochemically (FT4 consistently $>50 \mathrm{pg} / \mathrm{ml}$, FT3 consistently $>20$ $\mathrm{pg} / \mathrm{ml}$, TSI increased to $501 \%$ ) and thyroid volume increased to $70 \mathrm{ml}$. Finally, the patient agreed to undergo surgery prior to the appearance of a lifethreatening thyroid storm. A minimally invasive video-assisted total thyroidectomy (MIVAT) under local anaesthesia was performed. In preparation for MIVAT, 2 months before the surgical operation, lithium was started (300 mg/day), then increased to $750 \mathrm{mg}$ /day and eventually stopped 7 days prior to MIVAT. Lugol's solution was started when lithium

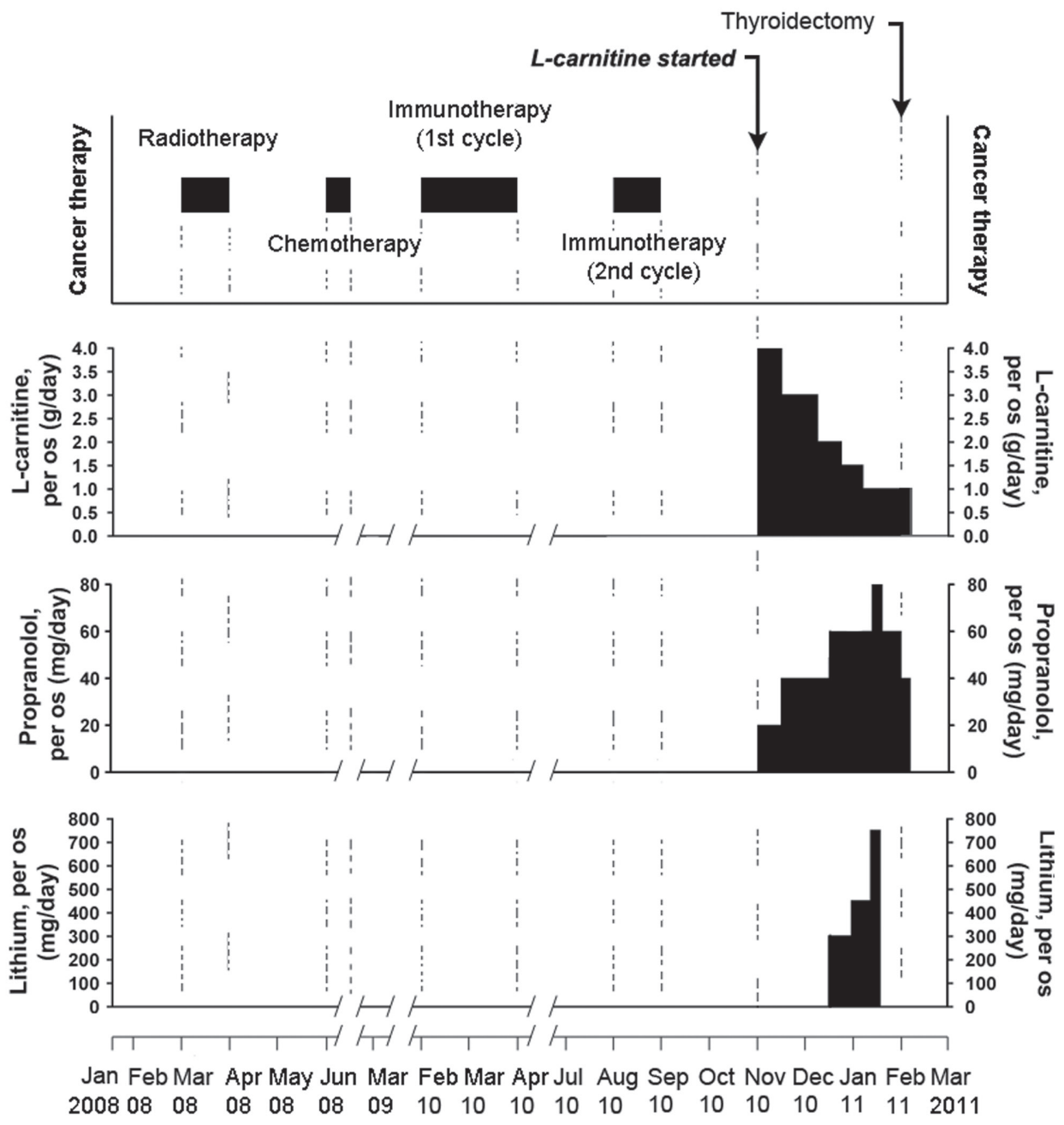

Figure 1. Summary of the management of synovial sarcoma, which was surgically removed in February 2008, and hyperthyroidism. 

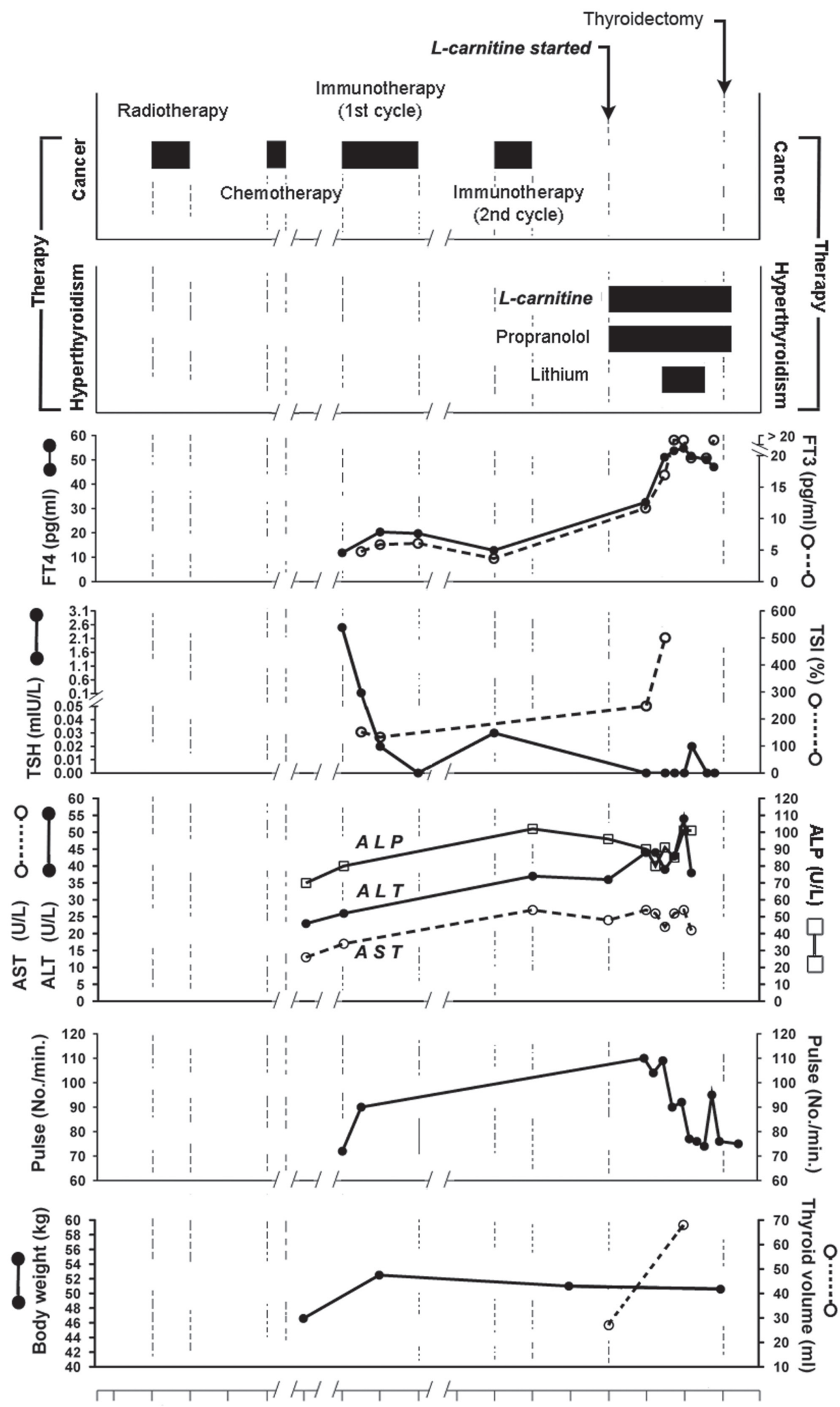

Jan Feb Mar Apr May Jun Mar Feb Mar Apr Jul Aug Sep Oct Nov Dec Jan Feb Mar

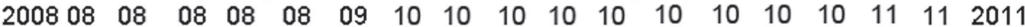

Figure 2. Pertinent clinical and biochemical indices related to hyperthyroidism, with their pattern prior to and after its treatment, for the doses of L-carnitine, propranolol and lithium, see Figure 1. ALP: alkaline phosphatase; ALT: alanine-aminotransferase; AST: aspartate-aminotransferase; FT3: free triiodothyronine; FT4: free thyroxine; TSH: thyroid stimulating hormone. 
was stopped and L-carnitine continued at $1 \mathrm{~g} /$ day. MIVAT was successful and uneventful so that Lcarnitine was stopped 4 days following MIVAT. Body weight decreased by $1.5 \mathrm{Kg}$ during the subsequent 8 months (52.5 to $51 \mathrm{Kg}$ ). However, just prior to thyroidectomy, body weight was $50.6 \mathrm{Kg}$. This shows that during treatment with L-carnitine the patient lost only $0.4 \mathrm{Kg}$, though hyperthyroidism was biochemically much worse.

\section{DISCUSSION}

L-carnitine is a ubiquitous amine involved in energy production and its tissue concentrations decrease in the hyperthyroid states. ${ }^{15}$ Studies on cultures of skin cells (fibroblasts), hepatic cells and neuronal cells showed that L-carnitine dose-dependently inhibits entry into the cell nuclei of the two thyroid hormones but not thyroid hormone binding to the cognate nuclear receptors..$^{10}$ Based on these experimental data ${ }^{10}$ and the clinical trial on iatrogenic hyperthyroidism, ${ }^{11}$ which demonstrated that L-carnitine is capable of both reversing pre-existing hyperthyroid symptoms/signs and preventing them from appearing de novo, the use of L-carnitine has been proposed even in thyroid storms. ${ }^{11}$ Thyroid storm is a relatively rare but lifethreatening syndrome characterized by exaggerated manifestations of thyrotoxicosis. ${ }^{3}$ It is triggered by precipitating events like infections, surgery, trauma, iodinated contrast dyes, hypoglycaemia, parturition, vigorous palpation of thyroid, emotional stress, withdrawal of ATDs, ${ }^{131}$ I therapy, diabetic ketoacidosis, pulmonary thromboembolism, cerebrovascular accident. Thyroid storm requires high doses of ATDs (e.g., $20 \mathrm{mg}$ of methimazole every 4 hours) plus supportive therapy.

Until now, apart from the presented case, there are only two reports on the use of L-carnitine in severe hyperthyroidism. The first concerned a young, fragile and cardiopathic man who survived three subsequent thyroid storms that were managed with oral L-carnitine and low doses of methimazole..$^{12}$ In that man, ${ }^{12}$ as well as in our patient, hyperthyroidism had been triggered by external circumstances. In the present patient, the triggers for the onset of hyperthyroidism and for its aggravation were the two cycles of vaccination. Indeed, in a clinical trial on nine ovarian cancer women, two cases of hypothyroidism and one case of subclinical and self-limiting hyperthyroidism induced by NY-ESO-1 peptide vaccine were reported. ${ }^{14}$ The man was treated, over a period of 7 months, with a fixed dose of L-carnitine $(2 \mathrm{~g} / \mathrm{d})$ and $5-15 \mathrm{mg} / \mathrm{d}$ methimazole plus corticosteroids and benzodiazepines. ${ }^{12}$ The woman used L-carnitine, over a period of 3 months, at a progressively lower dose (4 to $1 \mathrm{~g} /$ day) in conjunction with propranolol (20 to 80 $\mathrm{mg} / \mathrm{d}$ ) and without ATDs or other supportive therapies. She underwent total thyroidectomy while still biochemically hyperthyroid under $1 \mathrm{~g} / \mathrm{d}$ L-carnitine plus $60 \mathrm{mg} / \mathrm{d}$ propranolol. More recently, another patient with thyroid storm was treated with L-carnitine (i.v. $75 \mathrm{mg} / \mathrm{kg} / \mathrm{d}$ ), which led to unexpected awakening from a comatose state..$^{16} \mathrm{~L}$-carnitine was used as rescue therapy in that patient, already treated with propylthiouracile (per os $200 \mathrm{mg}$ tid), propranolol (i.v. $1 \mathrm{mg} / \mathrm{h}$ ) and methylpredisonolone (i.v. $1 \mathrm{mg}$ / $\mathrm{kg} / \mathrm{d}$ ), but with a severe neurological status. ${ }^{16}$

The beneficial effect of L-carnitine in antagonizing thyroid hormone-elicited clinical symptoms is also reflected by the antagonism in a number of thyroid hormone-elicited biochemical changes, including the hyperthyroidism-associated increase in serum ALP, ALT and AST. ${ }^{11}$ As shown in Figure 2, hyperthyroidism increased serum levels of all three enzymes, but this increase was blocked and reversed by L-carnitine. An upward trend of the three enzymes occurred as the daily dose of L-carnitine was scaled down.

\section{CONCLUSIONS}

In brief, this case confirms the great benefits provided by L-carnitine (without combination with ATDs) in serious forms of hyperthyroidism, even in clinically compromised patients. We strongly believe that the role of L-carnitine should be advanced from that of mere "ancillary" therapy. Use of L-carnitine should be available for thyroid storms, hyperthyroidism in pregnancy and postpartum, destructive forms of hyperthyroidism, iatrogenic hyperthyroidism, hyperthyroidism in patients with liver diseases and/or haematologic diseases, allergies to all ATDs, thyroid hormone resistance syndrome, preparation for thyroidectomy in selected patients. We also anticipate very low rates of ATDs-related side effects 
in patients co-treated with L-carnitine and low doses of any ATD.

\section{REFERENCES}

1. Cooper DS, 2003 Hyperthyroidism. Lancet 9: 459-468.

2. Burch HB, Burman KD, Cooper DS, 2011 A 2011 survey of current practice in the management of Graves' disease. 81st Meeting of the American Thyroid Association, Indian Wells, Ca (Abstract O-184).

3. Wartofsky L, 2000 Thyrotoxic storm. In: Braverman LE, Utiger RD (eds), Werner and Ingbar's, The Thyroid: A Fundamental and Clinical Text. 8th ed. Philadelphia, Pennsylvania: Lippincott Williams \& Wilkins, pp, 679684.

4. Benvenga S, 1996 Benzodiazepine and remission of Graves' disease. Thyroid 6: 659-660.

5. Vita R, Lapa D, Vita G, et al, 2009 A patient with stressrelated onset and exacerbations of Graves' disease. Nat Clin Pract Endocrinol Metab 5: 55-61.

6. Solomon BL, Wartofsky L, Burman KD, 1993 Adjunctive cholestyramine therapy in thyrotoxicosis. Clin Endocrinol (Oxf) 38: 39-43.

7. Tsai WC, Pei D, Wang TF, et al, 2005 The effect of combination therapy with propylthiouracil and cholestyramine in the treatment of Graves' hyperthyroidism. Clin Endocrinol (Oxf) 62: 521-524.

8. Hagag P, Nissenbaum H, Weiss M, 1998 Role of colestipol in the treatment of hyperthyroidism. J Endocrinol Invest 21: 725-731.
9. Azezli AD, Bayraktaroglu T, Orhan Y, 2007 The use of konjac glucomannan to lower serum thyroid hormones in hyperthyroidism. J Am Coll Nutr 26: 663-668.

10. Benvenga S, Lakshmanan M, Trimarchi F, 2000 Carnitine is a naturally occurring inhibitor of thyroid hormone nuclear uptake. Thyroid 10: 1043-1050.

11. Benvenga S, Ruggeri RM, Russo A, et al, 2001 Usefulness of L-carnitine, a naturally occurring inhibitor of thyroid hormone action, in iatrogenic hyperthyroidism: a randomized, double-blind, placebo-controlled clinical trial. J Clin Endocrinol Metab 86: 3579-3594.

12. Benvenga S, Lapa D, Cannavò S, et al, 2003 Successive thyroid storms treated with L-carnitine and low-dose methimazole. Am J Med 115: 417-418.

13. Kragie L, Doyle D, 1992 Benzodiazepines inhibit temperature-dependent L-[125I] triiodothyronine accumulation into human liver, human neuroblast, and rat pituitary cell lines. Endocrinology 130: 1211-1216.

14. Diefenbach CS, Gnjatic S, Sabbatini P, et al, 2008 Safety and immunogenicity study of NY-ESO-1b peptide and montanide ISA-51 vaccination of patients with epithelial ovarian cancer in high-risk first remission. Clin Cancer Res 14: 2740-2748.

15. Famularo G, Matricardi F, Nucera E, et al 1997 Carnitine deficiency: primary and secondary syndromes. In: De Simone C, Famularo G (eds), Carnitine Today. Austin, Texas: RG Landes, pp, 119-161.

16. Kimmoun A, Munagamage G, Dessalles N, et al, 2011 Unexpected awakening from comatose thyroid storm after a single intravenous injection of L-carnitine. Intensive Care Med 37: 1716-1717. 